\title{
ANÁLISE CRÍTICA DE MATERIAIS E CAMPANHAS DE PREVENÇÃO À AIDS
}

\author{
Marcio Schiavo \\ Eliesio Nogueira Moreira
}

Resumo: Neste artigo, apresentam-se as conclusões e recomendações do estudo Análise Critica de Materiais e Campanhas de Prevenção à AIDS, realizado para a Coordenação Nacional de DST/AIDS, do Ministério da Saúde. 0 estudo se desenvolveu no período de março a julho de 1997 e abrangeu 96 diferentes peças e materiais informativos, educativos e motivacionais então em uso pelas organizações governamentais e não-governamentais da área. Esses materiais foram analisados em seus diversos aspectos comunicacionais, tais como: público-alvo; conteúdos conceituais e enfoque; natureza da mensagem; tipo de material e estratégia de utilização; niveis de aceitação e compreensibilidade; eficácia e efetividade das mensagens. 0 estudo destinou-se a subsidiar a CN DST/AIDS no processo de ampliação e aprimoramento das ações de comunicação para prevenção à AIDS, tendo em vista a próxima (19982002) implementação do AIDS II - programa desenvolvido pelo Governo Federal em parceria com o Banco Mundial (BIRD).

Palavras Chaves: Prevenção à AIDS; Informação \& Educação; Educação Para a Saúde

\section{Introdução}

Este documento apresenta os resultados da Análise Critica de Materiais e Campanhas de Prevenção à AIDS, pesquisa realizada para a 
Coordenação Nacional de DST/AIDS (CN DST/AIDS), órgão vinculado à Secretaria de Assistência à Saúde, do Ministério da Saúde. Os trabalhos se desenvolveram no período de 07 de março a 06 de julho de 1997, tendo sido analisados 96 peças e materiais selecionados pelos técnicos da CN DST/AIDS e que se distribuiam por três categorias: a) materiais informativo-educativos, dirigidos à população em geral e/ou segmentos sociais selecionados (jornais, boletins, vídeos, cartilhas, folders, displays e cartazes); b) materiais instrucionais, dirigidos a profissionais de saúde ou multiplicadores (livros, manuais, guias e kits; c) materiais de registro e divulgação interinstitucional (catálogos, anais e relatórios).

$\mathrm{Na}$ análise dos materiais e peças, foram empregados três procedimentos metodológicos diversos. Inicialmente, os consultores fizeram uma Análise Preliminar, na qual revisou-se a classificação adotada pelos técnicos da CN DST/AIDS e identificaram-se alguns aspectos referentes às audiências selecionadas, meios utilizados, linguagens prevalentes, tipos de mensagem, natureza dos conteúdos e posicionamento da mensagem junto aos públicos-alvo. Todos os achados dos consultores foram, posteriormente, confrontados com os resultados dos grupos focais e dos contatos com produtores e agentes multiplicadores.

Em seguida, os consultores deram início ao planejamento e organização dos Grupos Focais, incluindo a definição das cidades, datas e locais de realização das sessões, além da seleção de participantes, elaboração dos instrumentais necessários e preparação das peças que seriam submetidas à análise dos grupos. Foram elaborados roteiros de discussão tanto para os grupos constituídos de produtores e/ou multiplicadores (Anexo 2) representantes de OGs e ONGs que atuam na prevenção às DST/AIDS quanto para os grupos formados por pessoas representativas dos vários públicos-alvo aos quais os materiais se destinam (Anexo 3). 0s grupos focais tiveram lugar no Rio de Janeiro, Brasília e Salvador - onde se realizaram duas sessões com cada categoria de participantes, incluindo os seguintes públicos-alvo: a) pré-adolescentes e adolescentes, homens e mulheres, na faixa etária dos 12 aos 18 anos, matriculados em escolas privadas de $1^{\circ}$. e $2^{\circ}$. graus; b) jovens de 19 a 24 anos, homens e mulheres sexualmente ativos, solteiros e casados ou unidos; c) homens e mulheres 
adultos, sexualmente ativos e solteiros; d) homens que fazem sexo com homens ("homossexuais" e "bissexuais"); e) mulheres/parceiras de homens que têm probabilidades de manter sexo casual; f) mulheres profissionais do sexo.

Os consultores também realizaram várias Entrevistas Formais (com gerentes de projetos e agentes multiplicadores ou facilitadores) e Informais (com representantes de públicos-alvo diversos). Nas entrevistas formais, foram contactadas nove ONGs que promovem ações de prevenção da AIDS sediadas no Estado do Rio de Janeiro, selecionadas no documento “Catálogo de Organizações Não-Governamentais: DST/AIDS - 1996", editado pelo PN DST/AIDS ${ }^{1}$, do Ministério da Saúde. Nas entrevistas informais, por sua vez, colheram-se depoimentos de diversos representantes de segmentos sociais selecionados, entre os quais: mulheres profissionais do sexo; travestis e garotos de programa ("michês"); homens que fazem sexo com homens; meninos e meninas em situação de elevado risco social; usuários de drogas injetáveis; homens que fazem sexo casual ou de risco; mulheres e/ou parceiras de homens que fazem sexo com homens e/ou de usuários de drogas injetáveis; caminhoneiros; meninos e meninas internos em instituições correcionais; e mulheres casadas.

\section{Meios e Materiais Utilizados}

Foram enviados aos consultores, para análise, 96 diferentes peças e materiais destinados à prevenção das DST/AIDS, selecionados pela própria CN DST/AIDS. Assim, não foram analisados os materiais de conteúdo técnico-especializado (vários Manuais e a maioria dos Guias) não seriam analisados - o mesmo ocorrendo com os que se constituiam em registro de eventos ou atividades (Relatórios e Boletins) ou em materiais para comunicação interinstitucional (Catálogos). Deste modo,

'Centro de Documentação, Informação e Comunicação (CDIC) - PN DST/AIDS. Catálogo de Organizações Não-Governamentais: DST/AIDS. Brasilia, Ministério da Saúde, 3a ${ }^{\text {a }}$ ed., 1997. 
o total de 96 materiais e peças a serem analisados incluiram Vídeos, Guia, Displays, Cartilhas, Folders, Manuais, Jornais e Cartazes, como se pode ver no Quadro 1. Segue-se a análise desses materiais:

Nota-se a predominância de materiais impressos, destinados à distribuição pessoal (Cartilhas e Folders) ou exposição (Cartazes). Juntos, esses materiais somam 51 peças ( $53 \%$ do total). Em conjunto com os demais impressos, chega-se a 67 materiais (70\% do total). Em vídeo, há 29 peças (30\% do total), sendo que muitos são de média duração destinando-se a ações educativas junto a grupos selecionados (operários, adolescentes, mulheres e portadores do HIV/doentes de AIDS). A concentração nos materiais impressos parece em desacordo com a cultura da imagem predominante no País. Contudo, as mensagens em vídeo (sobretudo, quando veiculadas via TV) alcançam audiência muito superior à atingida com as peças impressas, o que se coaduna com o objetivo de dar ampla difusão à questão da AIDS.

Quadro 1:

Distribuição dos Materiais Segundo os Diferentes Tipos

\begin{tabular}{|l|c|c|}
\hline Tipos de Materiais & Quantidade Analisada & \% do Total \\
\hline Vídeos/Spots de TV & 29 & 30,2 \\
\hline Guia & 01 & 1,0 \\
\hline Displays & 03 & 3,1 \\
\hline Cartilhas & 18 & 18,7 \\
\hline Folders & 22 & 23,0 \\
\hline Manuais & 08 & 8,3 \\
\hline Jornais & 04 & 4,2 \\
\hline Cartazes & 11 & 11,5 \\
\hline Total & 96 & 100 \\
\hline
\end{tabular}

Além disso, parece coerente com as estratégias de IEC da CN DST/AIDS, que privilegiam a descentralização das ações, a articulação e o 
envolvimento de diferentes atores sociais e o estabelecimento de parcerias, com a CN DST/AIDS atuando mais como responsável pelo estabelecimento de políticas e diretrizes e fomentador de ações nos niveis dos demais agentes sociais envolvidos, e menos como agente executor. Neste contexto, destacam-se as parcerias com diferentes ONGs e OGs que atuam na prevenção da AIDS, no âmbito dos programas de aproximação, onde vídeos podem ser utilizados, mas os materiais impressos são imprescindiveis como apoio e reforço às palestras educativas e atividades de aconselhamento, assim como para motivar e articular pessoas e comunidades.

Contudo, é de se observar dois aspectos importantes. Em primeiro lugar, a virtual ausência de materiais especificamente produzidos para o público analfabeto e/ou analfabeto funcional. Sabendo-se que, cerca de 25\% da população brasileira estão nessa condição, essa parece uma lacuna no amplo e eficaz programa de IEC desenvolvido e/ou fomentado pela CN DST/AIDS. Outro aspecto a considerar é também a ausência de materiais para veiculação em rádio. Certamente, o que se faz com freqüência é aproveitar o áudio dos spots produzidos para TV para a veiculação em emissoras de rádio. Contudo, apesar das adaptações feitas, nem sempre isso é efetivo. Afinal, nos spots para TV, o texto é um elemento de suporte, pois o mais importante são as imagens, enquanto nos spots para rádio, simplesmente não há imagem. Além disso, os públicos atingidos pelo rádio e pela TV são, essencial ou conjunturalmente, bastante diferenciados, o mesmo acontecendo com as situações em que se ouve rádio ou assiste TV. Tudo isso precisa ser levado em consideração, o que não recomenda a simples utilização do áudio do vídeo para veiculação em rádio.

\section{Tipos de Mensagem}

Os tipos e a natureza das mensagens admitem classificações diferenciadas, de acordo com a corrente da Ciência da Informação com que se trabalha. Uma das classificações mais amplamente aceitas e 
utilizadas - numa versão simplificada -, utilizando cinco diferentes categorias, classifica as mensagens do modo como se vê abaixo ${ }^{2}$. 0s exemplos foram colhidos na cartilha Como Evitar as Doenças Sexualmente Transmissiveis ${ }^{3}$ :

- Informativa - É aquela que divulga um fato ou conceito, integrando-o ao repertório de conhecimentos do públicođlvo. Exemplo: "A AIDS pode ser transmitida através da prática do sexo (vaginal, anal ou oral) com pessoa infectada, através do sangue contaminado, ou da mãe infectada para o filho - antes, durante ou após o parto" (pag. 8);

- Motivacional - É a mensagem que tem a intenção préestabelecida de formar uma opinião ou conceito, induzindo o público-alvo a agir de uma forma ou sentido determinado. Exemplo: "Se você sentir alguns desses sintomas, procure imediatamente o médico ou o posto de saúde mais próximo. A automedicação é perigosa” (pag. 13);

- Educativa - É aquela que apresenta uma série de diferentes informações sobre um tema determinado, de maneira processual e de modo a propiciar ao públicoalvo conteúdos e conhecimentos para uma tomada de decisão ou mudança de comportamentos, atitudes e práticas. Exemplo: “Esta é uma das mais comuns, entre as doenças transmitidas sexualmente. Se, de dois a oito dias após a relação sexual, o homem ou a mulher começarem a sentir ardência e dificuldade ao urinar, provavelmente, contraíram gonorréia. Eles podem notar, também, um corrimento de cor amarelada ou esverdeada ou, até mesmo, com sangue" (pag. 10);

\footnotetext{
${ }^{2}$ ATUCHA, L. M. A. e SCHIAVO, M. R. Mensaje: Inducción o Libertad de Decisión. New York, Federação Internacional de Planejamento Familiar (IPPF), fevereiro de 1976 (mimeo), $36 \mathrm{p}$.

${ }^{3}$ PN DST/AIDS. Como Evitar as Doenças Sexualmente Transmissiveis. Brasilia, s/d., 22p.
} 
- Informativo-Motivacional - Este tipo de mensagem, além de divulgar um fato ou conceito, procura induzir o público-alvo a agir de uma forma ou realizar uma ação pré-determinada. Exemplo: "Nem todo corrimento é sintoma de doença transmitida pelo ato sexual. Corrimentos são comuns em todas as mulheres. Contudo, só o médico poderá fazer o diagnóstico correto e indicar o tratamento adequado" (pag. 11);

- Informativo-Educativa - É aquela que apresenta os fatos e conceitos de maneira processual, de modo que cada informação depende da anterior para ser compreendida e se completa na informação seguinte. Exemplo:

“Também conhecida como crista de galo, figueira ou cavalo de crista, esta doença (condiloma acuminado) causa o aparecimento de verrugas na região genital e/ou anal. Bem no início da doença, pode haver apenas uma ou duas verrugas pequenas. Nessa época, a doença não faz grandes estragos, porque o tratamento é muito fácil, e a cura vem em poucos dias. Mas, se a pessoa não procurar logo o médico, as verrugas começam a crescer e a se espalhar, ficando uma bem juntinha da outra, parecendo uma couve-flor. E aí, dependendo do tempo, às vezes, é preciso fazer uma operação para a pessoa ficar curada" (pag. 17).

No Quadro 2, a seguir, pode-se ver a distribuição das peças e dos materiais analisados segundo os tipos de mensagem neles predominantes. É importante sublinhar, neste caso, que a grande maioria dos materiais destinados à prevenção das DST/AIDS apresenta, por assim dizer, uma articulação lógica dos diferentes tipos de mensagens - tendente a cumprir ora o objetivo de informar, ora o de motivar e/ou educar os respectivos públicos-alvo. Assim, considerando-se o conjunto de mensagens veiculadas num mesmo material, conclui-se que estão sendo relativamente bem exploradas as várias funções da comunicação. 
se maior coerência com os objetivos do programa de comunicação para prevenção das DST/AIDS. Com efeito, nota-se uma grande predominância das mensagens e conteúdos preventivos, em detrimento dos conteúdos de natureza assistencial, emocional ou múltipla. Também são vários os critérios disponíveis para a classificação de conteúdos conceituais. 0 que será explicitado a seguir foi estabelecido considerando-se os diversos fatores intervenientes na comunicação para a prevenção da AIDS (ações preventivas junto à população em geral e segmentos selecionados, serviços sociais e de saúde de apoio, assistência aos portadores do HIV e/ou doentes de AIDS), bem como os diferentes meios e materiais de comunicação utilizados:

- Preventivo - É o conteúdo cujo foco central são as medidas que devem ser adotadas como estratégia de preservação da saúde e/ou de redução dos riscos de exposição ao HIV. Incluemse, neste caso, as informações ou orientações sobre o sexo seguro (diminuição do número de parceiros, adoção de práticas que não envolvam contato com esperma, manutenção da monogamia e da fidelidade mútua, uso consistente do preservativo e uso, apenas, de agulhas e seringas descartáveis);

- Assistencial - Quando o principal aspecto abordado se refere a medidas de tratamento das DST/AIDS ou, também, aos serviços sociais de apoio eventualmente postos à disposição dos portadores do HIV e/ou doentes de AIDS. Incluem-se, nesta categoria, mensagens que divulgam serviços ou centros de atendimento médico-hospitalar, grupos de auto-ajuda e/ou medidas terapêuticas ou, ainda, que orientam os portadores, doentes seus familiares a respeito da convivência com a AIDS;

- Emocional - É o conteúdo que apela para os aspectos sentimentais e psicológicos, propiciando identificações e/ ou projeções de pessoas e fatos que expressam alegria ou tristeza, prazer ou dor, desânimo ou esperança, convivência 
ou solidão, etc. Estão neste caso as mensagens que mostram o doente de AIDS como um "coitadinho", solitário e condenado à morte prematura, bem como aquelas que buscam atemorizar o público-alvo para provocar mudanças de práticas e comportamentos;

- Múltiplo - Quando a mensagem não é suficientemente clara para que se possa inclui-la - com segurança - numa das três categorias anteriores ou, também, quando o conteúdo apresenta-se com forte entrelaçamento dos aspectos preventivos, assistenciais e emocionais.

Quadro 3:

Distribuição dos Materiais Segundo os Conteúdos Prevalentes

\begin{tabular}{|l|c|c|}
\hline Conteúdos Conceituais & No. de Materiais & \% do Total \\
\hline Preventivo & 57 & 59,4 \\
\hline Assistencial & 14 & 14,6 \\
\hline Emocional & 11 & 11,4 \\
\hline Múltiplo & 14 & 14,6 \\
\hline & & 100 \\
\hline Total & 96 & \\
\hline
\end{tabular}

0 Quadro 3 apresenta a distribuição dos materiais analisados segundo os conteúdos conceituais predominantes. Nota-se que, em consonância com os objetivos principais das ações de informação, educação e comunicação (IEC) sobre as DST/AIDS, os conteúdos de natureza preventiva predominam em 57 diferentes materiais e peças $(59,4 \%$ do total). Já em outros 14 materiais (14,6\%), o conteúdo predominante é o de natureza assistencial, enquanto os conteúdos emocional e múltiplo predominam em 11 (11,4\% do total) e 14 (14,6\%) materiais e peças, respectivamente. Destaca-se, neste caso, uma distorção no manejo e articulação dos diversos tipos de mensagem e conteúdos conceituais prevalentes. Com efeito, se uma grande parcela dos materiais e peças 
contém mensagens de natureza motivacional, seria de se esperar uma maior prevalência de conteúdos emocionais, que constituem a matériaprima fundamental da linguagem publicitária - a mais adequada à consecução dos objetivos de motivar ou induzir comportamentos junto aos públicos-alvo. Todavia, não é o que acontece: em desacordo com a boa técnica de comunicação, busca-se motivar por meio da informação. Essa distorção apresenta-se de forma ainda mais clara quando se cruzam os dados relativos aos tipos de mensagem e aos conteúdos prevalentes nos materiais, como se pode verificar no Quadro 4. Os conteúdos emocionais aparecem como predominantes não apenas em peças e materiais de natureza motivacional $(5,2 \%$ de todos os materiais analisados) e/ou informativo-motivacional (3,1\%), mas também em alguns daqueles que seriam de natureza, essencialmente, informativa $(2,1 \%)$ ou educativa $(1,0 \%)$. Isso denota que, de certa maneira, a linguagem e as estratégias publicitárias vêm contaminando as atividades de IEC destinadas à prevenção das DST/AIDS. Se, por um lado, isso contribui para a ampla e rápida disseminação de informações sobre essas enfermidades, por outro, impõe enormes dificuldades ou obstáculos à abordagem dos conteúdos éticos e educativos - essenciais às mudanças de comportamentos, atitudes e práticas.

\section{Quadro 4:}

Distribuição dos Materiais Segundo Tipo de Mensagem e Conteúdos

\begin{tabular}{|c|c|c|c|}
\hline Tipos de Mensagem & Conteúdos & $\mathrm{N}^{\circ}$. de Materiais & $\%$ do Total \\
\hline \multirow[t]{4}{*}{ Informativa } & - Preventivo & 16 & 16,7 \\
\hline & - Assistencial & 09 & 9,4 \\
\hline & - Emocional & 02 & 2,1 \\
\hline & - Múltiplo & 04 & 4,2 \\
\hline \multirow[t]{4}{*}{ Motivacional } & - Preventivo & 10 & 10,4 \\
\hline & -Assistencial & - & - \\
\hline & - Emocional & 05 & 5,2 \\
\hline & - Múltiplo & 03 & 3,1 \\
\hline
\end{tabular}




\begin{tabular}{|c|c|c|c|}
\hline \multirow[t]{4}{*}{ Educativa } & - Preventivo & 05 & 5,2 \\
\hline & - Assistencial & - & - \\
\hline & - Emocional & 01 & 1,0 \\
\hline & - Múltiplo & 01 & 1,0 \\
\hline \multirow[t]{4}{*}{ Informativo-Motivacional } & - Preventivo & 19 & 19,8 \\
\hline & - Assistencial & 03 & 3,1 \\
\hline & - Emocional & 03 & 3,1 \\
\hline & - Múltiplo & 04 & 4,2 \\
\hline \multirow[t]{4}{*}{ Informativo-Educativa } & - Preventivo & 07 & 7,3 \\
\hline & - Assistencial & 02 & 2,1 \\
\hline & - Emocional & - & - \\
\hline & - Múltiplo & 02 & 2,1 \\
\hline Total & & 96 & 100 \\
\hline
\end{tabular}

Ainda a este respeito, alguns aspectos devem ser destacados. A prevalência de conteúdos de caráter múltiplo (que predominam em 14 diferentes materiais) é, relativamente, elevada. Isso denota uma conjugação de diferentes objetivos num mesmo material ou peça, o que constitui fator prejudicial à eficácia das mensagens. Por sua vez, os conteúdos assistenciais estão ausentes nos materiais predominantemente educativos e/ou motivacionais. Levando-se em conta que um dos públicos-alvo prioritários do programa de comunicação é o constituido por doentes de AIDS e portadores do HIV, essa é uma lacuna que requer providências imediatas. Sem dúvida, esses segmentos devem não apenas estar informados sobre os serviços e os locais de atendimento, como também precisam ser motivados a procurá-los.

\section{Públicos-Alvo Prioritários}

Quanto aos públicos-alvo, nota-se que os materiais analisados dirigemse a uma ampla variedade de segmentos sociais, cobrindo desde grupos 
com maiores probabilidades de exposição às DST/AIDS (homens que fazem sexo com homens, meninos(as) em situação de risco, usuários de drogas injetáveis (UDIs) e trabalhadoras sexuais) até os portadores do HIV e doentes de AIDS, passando por turistas, operários, adolescentes e jovens, homens e mulheres adultos, individuos que podem - em algum momento - assumir comportamentos de risco, seja no exercício da sexualidade e/ou uso de drogas injetáveis.

Um fato que chama a atenção é o grande número de materiais destinados à população em geral (Quadro 5). Há o consenso de que as percepções do corpo e seus usos, do exercício da sexualidade e dos riscos associados podem variar, significativamente, consoante as principais variáveis sócioeconômicas e culturais. Sabe-se, ainda, que a percepção da AIDS também é influenciada por essas variáveis, que podem determinar a maior ou menor prevalência de crenças infundadas, conceitos equivocados, mitos e preconceitos. Por tudo isso, também a autonomia para adotar práticas e comportamentos mais positivos e protetores varia muito entre os diferentes segmentos sociais. Assim sendo, resulta inapropriado e ineficaz que pouco mais de um-quinto dos materiais e peças não tenham sido submetidos a qualquer segmentação, estando dirigidos a uma audiência tão ampla, numerosa, dispersa e heterogênea.

Este fato possui implicações da mais alta relevância para o impacto obtido pelas ações de comunicação. Se o público-alvo for definido de forma não-segmentada, ficam inviabilizadas as mensagens preventivas específicas (por exemplo, aquelas que difundem práticas homossexuais que não envolvem contato com esperma ou as que mostram como injetar-se com segurança). Dirigidas à população em geral, essas mensagens caem no vazio - pois estes não são os comportamentos mais prevalentes. Por outro lado, omiti-las significa manter os riscos a que, em geral, se expõem os homens que fazem sexo com homens e UDIs.

\section{Quadro 5:}

Distribuição dos Materiais Segundo os Públicos-Alvo 


\begin{tabular}{|l|c|c|}
\hline Públicos-Alvo & No. de Materiais & \% do Total \\
\hline População em Geral & 20 & 20,83 \\
\hline Mulheres Adultas & 14 & 14,58 \\
\hline Homens Adultos & 06 & 6,25 \\
\hline Adolescentes & 05 & 5,21 \\
\hline Empresários & 02 & 2,08 \\
\hline Operários & 01 & 1,04 \\
\hline Educadores e Multiplicadores & 10 & 10,42 \\
\hline Homens e Mulheres Adultos & 14 & 14,58 \\
\hline Homens Homossexuais & 02 & 2,08 \\
\hline Homens Bissexuais & 03 & 3,13 \\
\hline Trabalhadores Sexuais & 03 & 3,13 \\
\hline Portadores do HIV/Doentes de AIDS & 09 & 9,38 \\
\hline Turistas & 04 & 4,17 \\
\hline Usuários de Drogas Injetáveis (UDIs) & 01 & 1,04 \\
\hline Profissionais de Saúde & 02 & 2,08 \\
\hline & & 100 \\
\hline Total & 96 & \\
\hline
\end{tabular}

É importante, neste caso, distinguir as campanhas e peças produzidas para veiculação nacional daquelas que possuem caráter local. No mais das vezes, as campanhas nacionais são as que se dirigem à população em geral - ou seja, a uma audiência não-segmentada. É sintomático o fato de que, nos grupos focais, a grande maioria dos participantes teve dificuldades para identificar as audiências que se pretendia atingir com os materiais e campanhas de caráter nacional - fato que não ocorreu, unicamente, com os materiais e peças dirigidos aos adolescentes. Em contrapartida, foi muito fácil a identificação dos públicos-alvo dos materiais e campanhas de caráter local - que, em geral, se dirigem a segmentos sociais selecionados, entre os quais trabalhadores sexuais (homens e mulheres), usuários de drogas injetáveis, homens que fazem sexo com homens ("homossexuais" e "bissexuais").

A não-segmentação da audiência implica, como já se ressaltou, na 
generalização da mensagem. Assim, é consenso que as campanhas nacionais têm chamado a atenção para a questão da AIDS, principalmente, mas também vêm contribuindo para distanciar o problema (os riscos de exposição ao HIV) de sua solução (adoção de práticas e comportamentos preventivos). Com efeito - e esse fato também foi ressaltado nos diferentes grupos focais realizados -, as campanhas difundem as informações básicas sobre a doença ("como se pega”, "como não se pega”, seu agente causador, sintomas, formas de prevenção, etc.), mas não são claras quanto aos benefícios reais advindos de uma mudança de práticas e comportamentos. Quer dizer: divulgam-se informações genéricas e superficiais (de resto, já do conhecimento da grande maioria da população), mas não se abordam conteúdos éticos e educativos que poderiam fundamentar mudanças comportamentais. Este fato decorre tanto da não-segmentação da audiência quanto da linguagem publicitária empregada e do meio mais utilizado na veiculação, em geral, a TV, que praticamente impõem o uso de informações fragmentadas e descontextualizadas. Neste contexto, devese adaptar as mensagens, a linguagem e os meios utilizados nas campanhas aos diversos públicos-alvo. Para tanto, é preciso segmentar a audiência, considerando as diferentes variáveis intervenientes nos comportamentos, atitudes e práticas das pessoas. Por exemplo, do total de 96 materiais, 15 são dirigidos a mulheres adultas, 05 a homens adultos e 14 a homens e mulheres adultos. Chega-se, portanto, a 34 diferentes materiais $(37,7 \%$ do total), dirigidos a homens e mulheres adultos, audiência que é, por certo, muito difusa e heterogênea. Sem dúvida, variáveis sócio-econômicas como renda familiar, níveis de instrução, faixa etária, estado civil, situação familiar, ocupação, local de moradia e trabalho precisam ser consideradas.

0 mesmo acontece com as variáveis que influenciam os comportamentos e práticas, como atitudes, valores, práticas, opiniões e crenças frente à saúde e sua preservação, ao exercício da sexualidade e ao HIV/AIDS, atitudes frente à possibilidade de vir a manter sexo casual, opções e espaços de lazer e convivência. Todos esses fatores são importantes para que se possa adequar as mensagens aos diferentes públicos-alvo, 
em termos de conteúdos, enfoque, linguagem e meios utilizados. Para tanto, é necessário realizar pesquisas periódicas junto a esses públicos, a fim de levantar informações sobre padrões de conduta e nuances comportamentais porventura existentes.

Ainda com respeito ao público-alvo, três aspectos devem ser destacados. 0 primeiro deles diz respeito à quantidade de materiais dirigidos às diversas audiências. Ora, teoricamente, a população em geral não adota preponderantemente práticas e comportamentos de risco, mais prevalentes em segmentos sociais selecionados. Deste modo, é de estranhar que haja 20 diferentes materiais dirigidos à população em geral e outros 34 materiais destinados a homens e mulheres adultos. Isto quer dizer que 56\% dos materiais não se dirigem a nenhum dos grupos expostos a maiores riscos, e sim, à população em geral. Está implicita, portanto, a percepção (equivocada) de que a grande maioria das pessoas mantêm comportamentos de risco. Em contrapartida, segmentos cujas práticas e comportamentos podem envolver maior risco (se não forem tomadas medidas preventivas), como homossexuais masculinos, bissexuais, mulheres profissionais do sexo, outros trabalhadores sexuais e usuários de drogas injetáveis contam, respectivamente, com apenas 02, 03, 02, 01 e 01 material. Ou seja: menos de $10 \%$ de todos os materiais produzidos destinam-se aos grupos com maiores possibilidades de exposição ao HIV.

0 segundo aspecto refere-se ao mix (conjunto) de materiais dirigidos, especificamente, a cada público-alvo (Quadro 6). Embora considerandose, apenas, os materiais e peças produzidos em maiores quantidades e/ ou que têm maior difusão, observa-se que somente para a população em geral, mulheres adultas, homens adultos, homens e mulheres, e portadores do HIV/doentes de AIDS poder-se-ia dizer que há um mix adequado, que, em geral, inclui videos, cartilhas, folders e cartazes embora com a limitação de não incluir mensagens radiofônicas. Os mix dirigidos a públicos mais segmentados, ao contrário, deixam muito a desejar. No caso dos adolescentes, por exemplo, sente-se falta de um cartaz de promoção do sexo seguro e/ou de estímulo ao uso consistente do preservativo, destinado à exposição em escolas, cursos particulares, 
clubes, flippers, shopping-centers, academias de ginástica, etc. Outros meios eficazes para este público também poderiam estar sendo utilizados, como mensagens visuais em máquinas de flippers ou expostas em discotecas, jingles musicais aproveitando os ritmos preferidos pelos jovens (rock, funk, rap, charm, etc.), mensagens educativas em revistas e suplementos dirigidas a adolescentes.

\section{Quadro 6:}

Distribuição dos Materiais Segundo os Públicos-Alvo

\begin{tabular}{|l|l|l|l|l|l|l|}
\hline Públicos-Alvo & Videos & Cartilhas & Folders & Manuais & Cartazes & Total \\
\hline População em Geral & 08 & 01 & 05 & - & 03 & 17 \\
\hline Mulheres Adultas & 07 & 05 & - & - & 01 & 13 \\
\hline Homens Adultos & 04 & - & 01 & - & 01 & 06 \\
\hline Adolescentes & 01 & 01 & 02 & - & - & 04 \\
\hline Empresários & 02 & - & - & - & - & 02 \\
\hline Operários & 01 & - & - & - & - & 01 \\
\hline Multiplicadores & - & 02 & - & 08 & 01 & 11 \\
\hline Homens/Mulheres & 01 & 04 & 03 & - & 03 & 11 \\
\hline "Homossexuais" & - & - & 02 & - & - & 02 \\
\hline "Bissexuais" & - & - & 02 & - & 01 & 03 \\
\hline Trabalhadores Sexuais & - & 01 & 02 & - & - & 03 \\
\hline Portadores do HIV & 05 & 03 & - & - & - & 08 \\
\hline Turistas & - & - & 04 & - & - & 04 \\
\hline UDIs & - & - & 01 & - & - & 01 \\
\hline Profissionais de Saúde & - & 01 & - & - & 01 & 02 \\
\hline & & & & & & \\
\hline Total & 29 & 18 & 22 & $\mathbf{0 8}$ & $\mathbf{1 1}$ & $\mathbf{8 8}$ \\
\hline
\end{tabular}

Obs.: Foram considerados, apenas, os materiais produzidos em maior quantidade e/ou que têm maior difusão. 0 guia, os três displays e os quatro jornais, num total de oito materiais, foram excluidos. 
A mesma inadequação de mix observa-se em relação a outros públicosalvo. Dirigidos a empresários, por exemplo, só há dois materiais (ambos em vídeo). Poder-se-ía, no caso utilizar também uma cartilha ou folder que mostrasse, claramente, os benefícios para a empresa que realizasse um trabalho preventivo das DST/AIDS junto aos seus empregados. Anúncios motivacionais também poderiam ser veiculados em revistas dirigidas às classes empresariais, assim como em publicações diversas editadas pelas entidades representativas da classe. Para os operários, também poderiam ser produzidas cartilhas ou folders educativos, além de cartazes motivacionais e de divulgação de serviços. Spots para rádio, mensagens educativas em jornais populares, painéis afixados em ônibus e cartazes afixados nos locais de trabalho, em terminais rodoviários e ferroviários também seriam eficazes para este público.

Finalmente, também chama a atenção a virtual ausência de materiais e mensagens especificamente dirigidos a públicos como os analfabetos e semi-analfabetos; mulheres casadas ou unidas com homens que fazem sexo com homens e/ou que são usuários de drogas injetáveis; caminhoneiros; internos do sistema penitenciário; meninos e meninas internos em instituições correcionais. Para analfabetos e semianalfabetos, seriam indicados histórias em quadrinhos sem textos e, sobretudo, spots para veiculação em emissoras de rádio e serviços de alto-falantes. No caso das mulheres casadas ou unidas com homens que fazem sexo com homens e/ou com UDIs, poderiam ser utilizados cartazes, folhetos e também spots para rádio e TV. Ressalte-se que esta é uma lacuna que, verdadeiramente, requer medidas urgentes, em vista da evolução do perfil epidemiológico da AIDS no Brasil, que indica crescente infecção de mulheres casadas ou unidas por seus parceiros que fazem sexo casual, são bissexuais e/ou usuários de drogas injetáveis. Para os demais públicos, seriam adequados cartazes informativos e motivacionais a serem afixados nos locais em que podem ser encontrados (postos de abastecimento, bares e restaurantes à beira das estradas, instituições prisionais e/ou correcionais, respectivamente). Cabe, ainda, destacar que para meninos e meninas em situação de risco social só há um material (vídeo) disponivel. É 
recomendável, portanto, produzir cartilhas e cartazes dirigidos a esse público, a fim de promover a prática do sexo seguro.

\section{Aspectos Relacionados à Mensagem}

Quanto à mensagem, o principal aspecto a ser observado é a relevância dos conteúdos abordados. Sem dúvida, as informações e orientações inseridas nos materiais devem ser aquelas que o público-alvo considera relevantes e demonstra o desejo de conhecer, e não, as que o educador ou comunicador considera importantes. No geral, os diversos materiais analisados concentram-se nas informações básicas sobre as caracteristicas das DST/AIDS, seus principais sintomas, formas de transmissão, progressão e possíveis distúrbios associados, além das estratégias e meios de prevenção, com ênfase no uso consistente do preservativo e/ou de seringas e agulhas descartáveis. Todavia, sobretudo em relação à AIDS, não são raros os casos de mensagens incompletas, ambiguas e/ou contraditórias. Por exemplo:

- A grande maioria dos materiais se apóia na fórmula "Assim Pega, Assim Não Pega”. No primeiro caso, invariavelmente, listam-se as quatro formas conhecidas de transmissão, a saber: a) Relações Sexuais (Sexo Oral, Anal ou Vaginal); b) Compartilhamento de Seringas e Agulhas; c) Transmissão Vertical (da mãe para o filho, antes ou durante o parto ou, ainda, durante o periodo de amamentação; d) Transfusões Sangüineas. Porém, apenas no caso das transfusões, é esclarecido que a pessoa só pode ser infectada "se o sangue estiver contaminado com o vírus”. Assim, a informação daí resultante é a de que em todas as relações sexuais e situações em que se compartilham seringas e agulhas, corre-se o risco de exposição ao HIV, o que não é verdade. Afinal, esse risco só existe quando uma das pessoas envolvidas é portadora do virus. 
- Na relação de situações e procedimentos do "Assim Não Pega", quase todos os materiais listam diferentes formas de contato pessoal (aperto de mão, abraço, beijo no rosto ou na boca, carícias) ou sexual (masturbação mútua, sexo nas coxas, beijo de lingua, massagem, banho de língua), uso comum de objetos ou utensilios (talheres, copos, pratos, toalhas, canetas, maçanetas, etc.), transportes ou sanitários públicos, saunas, piscinas, etc.), picadas de insetos e contato com secreções corporais (saliva, lágrimas e suor) como sendo situações em que não existem riscos de exposição ao HIV. Em contrapartida, raros são os materiais que procuram esclarecer crenças infundadas em relação às demais DST (como, por exemplo, a de que se pode contrair gonorréia sentando-se em bancos quentes ou pisando no chão frio após a relação sexual). A exceção, no caso, é a cartilha Como Evitar as Doenças Sexualmente Transmissiveis (dirigida à população em geral, homens e mulheres adultos).

- 0 uso do preservativo é apresentado, geralmente, como se esta fosse a única estratégia de sexo seguro. É o que se observa, por exemplo, no folder AIDS: Responsabilidade de Todos Nós, no vídeo Sem Vergonha de Ser Feliz e nos spots de TV Apoteose do Prazer, Medo de Afinar, Mulherengo e Brincando. Poucos são os materiais em que se procura difundir práticas sexuais de baixo risco (isto é, práticas não-penetrativas e/ou que não envolvem contato com esperma), como é feito nos folders Sexo, Homens \& AIDS (dirigido a homens que fazem sexo com homens) e Mais Seguro (homens adultos). E menos, ainda, são aqueles que fazem referência à redução de parceiros, abandono de relações casuais e/ou com parceiros desconhecidos, à abstinência sexual ou à fidelidade mútua entre parceiros sadios. Numa das 
histórias da cartilha Toda Vez e Sempre, essas estratégias aparecem - mas, de forma implícita.

- A quase totalidade dos materiais incluem informações detalhadas e processuais (do tipo passo-a-passo) sobre "como usar a camisinha", com exceção da cartilha Como Evitar as Doenças Sexualmente Transmissiveis, falha grave num material de tão boa qualidade e aceitação. No entanto, no mais das vezes, as ilustrações (essenciais para que se possa acompanhar o processo) são em número insuficiente para ilustrar os diferentes passos, são pouco claras e de tamanho reduzido, como acontece no folder DST/AIDS: 0 Que São e Como Prevenir e na cartilha Rapaz da Noite. Uma constante, também, é mostrar apenas uma parte da cintura do homem e o pênis (a(o) parceira(o) jamais aparece), para ilustrar a colocação do preservativo, o que pode ser observado até mesmo no álbum-seriado Doenças Sexualmente Transmissíveis (dirigido a agentes multiplicadores). Ora, para fazer sexo sozinho (masturbarse) não precisa usar preservativo. Por que, então, não utilizar sempre o casal, de preferência com a mulher colocando o preservativo no parceiro? Isso serviria para erotizar a camisinha, reduzindo as barreiras ao seu uso. Além disso, são raros os materiais em que se recomenda verificar a data de validade e as condições do produto (se está pegajoso ou quebradiço) e mais raros ainda os que incluem informações sobre sua adequada desembalagem. Sabe-se que, muitas vezes, o próprio usuário danifica o preservativo, ao abrir a embalagem de maneira apressada e pouco cuidadosa, usando os próprios dentes ou instrumentos cortantes, como facas e tesouras. Somente dois materiais fazem referência a isso: os folders Sexo, Homens \& AIDS ("Cuide. Não abra a embalagem da camisinha com os dentes e verifique a data de validade") 
e Fique Ligado: Vamos Falar de AIDS ("Abrir o envelope no sentido vertical; no picote, é claro, utilizando as mãos e não a boca, tesoura ou qualquer outro objeto cortante, afiado ou pontiagudo". 0 primeiro deles porém, não explica porquê. Deste modo, a advertência corre o sério risco de cair no vazio.

- De igual modo, quase todos os materiais advertem para que se dê preferência aos preservativos lubrificados, não recorrendo a quaisquer lubrificantes oleosos. Em geral, essa advertência é ilustrada com embalagens de vários lubrificantes (vaselina, óleos, cremes, manteiga, etc.), riscadas com um " $\mathrm{X}$ ", com o que se pretende denotar "uso ou procedimento proibido". No caso, apresenta-se a opção de utilizar lubrificantes à base de água. Contudo, quase nunca se informa quais os lubrificantes são à base de água. A exceção fica por conta do folder Sexo, Homens \& AIDS e da cartilha Mulheres: Saúde Reprodutiva e AIDS, que recomendam o uso de K-Y ou de Preserv-Gel.

- Observam-se, também, algumas contradições nas mensagens veiculadas tanto em alguns materiais especificos quanto entre dois ou mais materiais. No primeiro caso, destaca-se o Gibi da DST/AIDS (dirigido, basicamente, a mulheres adultas), que traz uma informação preocupante. Em dado momento, Zuleide, uma das personagens, pergunta: “E quando for transar com alguém, tem que usar camisinha?" E Mariléia, a personagem principal, responde: "Isso mesmo, tem que usar camisinha. Ou então dar um tempo, até conhecer muito bem a pessoa com quem você está se relacionando, estabelecendo uma relação 'mutuamente exclusiva'. Quer dizer: não transar com mais ninguém." Evidentemente, muitas das pessoas que agirem da maneira como Mariléia aconselha estarão correndo sérios 
os inseridos nos folders Fique Ligado: Vamos Falar de AIDS ("Se você toma baque na veia - que mal, hein! -, pelo menos tente usar a sua seringa") e Você Precisa Aprender a Transar com a Existência da AIDS ("Muita gente pensa que pra ficar numa boa, tem que entrar numa de usar drogas injetáveis. Estão por fora. Recuse essa viagem. Droga é uma grande furada").

- A não-segmentação da audiência, tentando-se atingir com o mesmo material um público mais amplo, provoca alguns fatos inusitados. Por exemplo, na série de folders produzidos pela Secretaria de Saúde de Pernambuco, as possibilidades de infecção vertical pelo HIV (da mãe para o filho, durante a gravidez ou parto e ao longo do aleitamento materno) são esclarecidas para públicos como homens que fazem sexo com homens ("homossexuais"), turistas e homens adultos, para os quais essas informações têm pouca relevância, mas não são enfatizadas nos materiais especificamente dirigidos a mulheres adultas.

-Uma informação altamente relevante para todas as pessoas, mas que comumente é ignorada nos materiais, é o tempo que pode decorrer entre a infecção pelo HIV e o aparecimento dos primeiros sintomas de AIDS. Isso é muito importante porque alguém pode estar transmitindo o HIV a outras pessoas sem saber que é portador. Uma das exceções, no caso, é o Gibi da AIDS, anteriormente referido. Em contrapartida, alguns raros materiais contêm informações comumente sonegadas. Assim ocorre, por exemplo, na revista em quadrinhos Onde Mora o Perigo - na qual se mostra o uso de dois preservativos para o sexo anal - e o folder Brasil: Terra dos Prazeres (dirigido a turistas), que chama a atenção para a interrelação entre o uso de drogas (inclusive, o álcool) e a menor inclinação para adotar práticas de sexo seguro. 
Finalmente, dois outros aspectos devem ser ressaltados. Em primeiro lugar, numa grande parcela dos materiais, omitem-se informações relativas a serviços e locais de atendimento a que se pode recorrer em busca de novas orientações e meios de prevenção (preservativos ou seringas e agulhas descartáveis). No folheto AIDS: Responsabilidade de Todos Nós, inclusive, faz-se o apelo "Venha nos visitar e conheça o nosso trabalho". Contudo, não traz o endereço da instituição, apenas o número de telefone de um de seus serviços, o Disque-AIDS. 0 segundo aspecto a ser destacado é que os materiais, em conjunto, mostram-se extremamente redundantes em termos de mensagens e conteúdos. Assim, deve-se estimular um maior compartilhamento de materiais entre as diferentes 0 NGs e 0 Gs que atuam na área. Essa estratégia implicaria, por certo, uma economia de recursos que poderiam ser utilizados para produzir materiais para públicos mais segmentados - necessidade que já se demonstrou.

\section{Aspectos Relacionados ao Enfoque}

Com relação ao enfoque e abordagem dos conteúdos, alguns materiais são exemplares. 0 Gibi da DST/AIDS (dirigido às mulheres adultas), por exemplo, apresenta uma história em quadrinhos simples e de fácil compreensão, mas apresenta-se como altamente eficaz - descontados os reparos já feitos quanto a, pelo menos, uma contradição em termos de mensagem. Expõe as informações de forma objetiva, processual, dialógica e lúdica, através da simpática personagem Mariléia, que apreendeu os conhecimentos em uma palestra proferida por um médico na empresa em que trabalha. Os principais sintomas de DST são, claramente, apresentados, recomendando-se que ao primeiro sinal de DST se procure logo o médico e avise à pessoa com que se manteve relações sexuais, "para que ela possa se tratar também". As formas de infecção pelo HIV também são apresentadas com clareza, estimulandose cuidados preventivos básicos como exigir agulhas e seringas descartáveis quanto foi tomar injeção, verificar o selo de garantia do sangue quanto precisar de transfusões e, sobretudo, usar preservativo nas relações sexuais. 
Este é um dos poucos materiais que faz referência à possibilidade de transmissão da AIDS em corrente, chamando a atenção para o fato de que as pessoas, em geral, desconhecem a história sexual dos parceiros. Isso é muito importante para estimular o uso consistente do preservativo. Outro aspecto positivo é a ênfase com que Mariléia se refere a um problema que afeta crescente número de mulheres: "Sabe o que o doutor contou? Tem mulher casada que pega o vírus da AIDS. 0 marido pula a cerca e arruma uma pessoa contaminada com o virus. A mulher nem desconfia... E ai já viu, né?" Mariléia também mostra como negociar o uso do preservativo ("A mulher tem que saber negociar. E com jeitinho, toda mulher consegue o que quer. Ela pode dizer que, sem camisinha, eles só vão brincar ou que ela não quer engravidar...") e, até mesmo, a negar-se ao sexo, caso o homem não queira usar o preservativo.

Esta cartilha se destaca, finalmente, por valorizar tanto o homem que se decide a usar o preservativo consistentemente quanto a mulher que insiste, conversa, explica e consegue convencê-lo a usar. Respondendo se o namorados sempre havia concordado em usar preservativo, Mariléia diz: "Bom, primeiro ele falou que não chupava bala com papel. Mas, depois, de muita conversa, ele concordou numa boa. É por isso que eu amo o Antônio. E a gente aprendeu, juntos, que camisinha não tira o prazer". Ao que Antônio responde: "Eu também amo a Mariléia. E ela sabe como convencer uma pessoa, ela sabe o que quer. Isso é que é mulher!" Sem dúvida, esse tipo de enfoque pode contribuir muito para reduzir as resistências femininas quanto a portar, sempre, o preservativo e a negociar o seu uso com o parceiro, sem termo de ser vista como uma mulher "fácil", "que transa com todo mundo" e/ou que "já saiu de casa pensando em transar com alguém". É imprescindivel criar condições - nos âmbitos cultural e conceitual - para que a mulher adquira maior autonomia para adquirir preservativos, propor e negociar o seu uso consistente com o parceiro.

Um outro material cujo enfoque e abordagem são perfeitamente adequados ao público-alvo é a revista em quadrinhos Onde Mora o Perigo - que segue uma linha problematizadora, apresentando a falta de informações e a prevalência de mitos e preconceitos, o conflito, a 
perda, a aprendizagem e a reconquista. Antônio e Dalva estão namorando. No motel, entre carícias ardentes, ela propõe: "Vamos por uma camisinha?" Ele responde diz que não tem e ela insiste: "Tudo bem, eu tenho". Ele, então, explica que não usa, que camisinha "corta o barato", que se ela está tão preocupada é porque “alguma coisa tem” e, por fim, acaba dizendo que se ela "anda com camisinha na bolsa, é porque deve transar com todo mundo". Ela diz que ele é um ignorante, e vai embora, deixando-o furioso.

Mais tarde, Antônio encontra Monalisa, uma trabalhadora sexual que está sendo jogada para fora do carro de um cliente porque negou-se a fazer sexo oral sem camisinha. Antônio ajuda Monalisa a levantar-se, conversam, e ele conta para ela que, logo na primeira transa com Dalva, a namorada "veio com papo de camisinha" e que ele não usa "porque me corta o barato". Monalisa leva Antônio para sua casa. Depois de um bom banho, ela veste o preservativo no pênis do rapaz e começa a excitá-lo com a boca. Antônio sobre pelas paredes de tanto prazer e ela pergunta: "E aí? Cortou o barato? Depois, eles fazem sexo vaginal e Antônio experimenta um longo e prazeroso orgasmo. Logo depois, ela estimula o rapaz à prática do sexo anal, dizendo: "Vamos por uma camisinha nova nele... depois, outra. E assim, usando dois preservativos, Antônio faz sexo anal com Monalisa, chegando a novo orgasmo.

Valeu a lição que Antônio recebeu de Monalisa. Ele procura Dalva e se desculpa com ela. Logo depois, os dois estão novamente no motel. Só que ele é o primeiro a pegar o preservativo, antes da penetração. Sensualmente, ela veste o pênis dele e transam apaixonadamente, com ele sentindo "o calor dela através da camisinha". No caso, foi muito eficaz e oportuno o uso de mensagens mediatizadas pelos sentimentos e emoções, para passar conteúdos preventivos, de cuidados com sipróprio e com o(a) parceiro(a) e de combate a mitos e preconceitos que ainda permeiam o uso do preservativo (como os de cortar o barato ou tirar a sensibilidade) e sua negociação por parte da mulher.

Outros dois exemplos de enfoque adequado às audiências podem ser apontados. Um deles é o Cordel da DST, material bastante criativo, com linguagem simples e estilo objetivo e progressivo. Altamente informativo 
e educativo, o folder apresenta os principais sintomas das DST mais comuns e da AIDS e as formas de preveni-las, com ênfase no uso do preservativo ("Diga não, se o cabra não quiser usar"). 0 segundo é a cartilha Toda Vez e Sempre, que apresenta três pequenas histórias em quadrinhos. De natureza problematizadora, dialógica e lúdica, a cartilha ensina a mulher a negociar o uso do preservativo com o parceiro, inclusive no caso de uma casal que mantém relações não-exclusivas. Nas três histórias, após a negociação, os respectivos parceiros aparecem concordando em usar preservativos.

Estes exemplos de excelência, contudo, não conseguem mascarar o fato de que a maioria dos materiais analisados apresentam problemas quanto ao enfoque e abordagem. Uma das questões mais sérias, a este respeito, é a ênfase na exceção. Sem dúvida, há muitas pessoas que assumem (pelo menos, alguma vez na vida) atitudes, práticas e comportamentos negativos ou de risco para sua saúde. Contudo, a grande maioria da população não costuma agir assim. A impressão que se tem é a de que, para os produtores de materiais destinados à prevenção das DST/AIDS todos os individuos sexualmente ativos são promíscuos e todos aqueles que usam drogas injetáveis compartilham, assiduamente, seringas e agulhas.

Essa visão distorcida faz com que as mensagens preventivas sejam construídas sob a perspectiva da doença, e não, da saúde. Com efeito, é grande a ênfase com que se veiculam informações sobre as DST e AIDS sexualmente transmissivel (características, sintomas, as formas de tratamento, sua progressão, conseqüências a médio e longo prazos e, obviamente, as formas de prevenção). Em contrapartida, pouco se informa sobre as atitudes, práticas e comportamentos positivos, de preservação e melhoria da saúde. Ou seja: ensina-se a evitar doenças, e não, a preservar a saúde. Isso pode ser constatado pelo fato de que a totalidade dos materiais apresenta as formas "como se pega" antes daquelas pelas quais "não se pega". Há, inclusive, um cartaz intitulado "Saiba Como Se Pega AIDS". Ora, ninguém em sã consciência está interessado em aprender como "pegar AIDS", e sim, em saber como evitá-la.

As mensagens preventivas construidas sob a perspectiva da doença abrem espaço, também, para uma verdadeira pedagogia da negatividade. Assim, são extremamente recorrentes nos materiais as mensagens do tipo "não 
faça sexo sem camisinha", "não vá pra cama sem ela", "não deixe o parceiro gozar na sua boca", "não arrisque a sua vida por uns trocados a mais", "sem camisinha, diga não", "não compartilhe seringas e agulhas". Ora, a boa técnica de comunicação recomenda que, ao contrário, se dê às questões um enfoque positivo, que se mostra bem mais eficaz. Assim, é preferivel utilizar mensagens do tipo "use sempre a camisinha em suas relações sexuais", "evite contato com esperma" ou "só use seringas e agulhas descartáveis". As pessoas desejam (e precisam) saber o que podem fazer para se prevenir das DST/AIDS, e não, aquilo que não podem fazer, pois se o fizerem estarão correndo riscos. Alinham-se, a seguir, outros problemas de enfoque observados nos materiais:

- Em geral, a questão das DST/AIDS é abordada de forma isolada, ou seja, fora do contexto mais amplo da sexualidade e da saúde sexual. Obviamente, essas doenças são caracterizadas como de transmissão, predominantemente, sexual. Porém, isso não basta. Para a consecução dos objetivos educativos e preventivos, ou seja, para que as pessoas se disponham a adotar mudanças comportamentais efetivas, é necessário que as DST/AIDS sejam percebidas como fenômenos intrinsecamente ligados às suas práticas, atitudes e comportamentos sexuais e, ainda, que esses fenômenos se refletem diretamente em suas possibilidades atuais e futuras de obter prazer e, até mesmo, em sua vida reprodutiva. Assim sendo, é preciso discutir mais as questões referentes às atitudes e práticas sexuais prevalentes nos diversos segmentos-alvo, cujos "scripts" sexuais (que envolvem aspectos de poder, dominação, submissão, auto-afirmação, de autonomia, transgressão, conquista, eroticidade do risco, etc.) são fatores determinantes para a maior ou menor possibilidade de exposição aos agentes causadores de DST e, particularmente, ao HIV. Neste sentido, as exceções, embora tímidas, são a cartilha Mulheres: Saúde Reprodutiva e AIDS e alguns materiais dirigidos a "homossexuais" e michês; 
- A mulher é, geralmente, apontada como a grande responsável por "convencer" o parceiro a usar camisinha. Evidentemente, sendo uma relação a dois, ambos os parceiros devem assumir sua parcela de responsabilidade na preservação da sua própria saúde e, também, a do(a) parceiro(a). Considerando-se, porém, que é o homem que usa a camisinha e ele, muitas vezes, se recusa a isso, caberia à mulher insistir, uma vez que é ela quem recebe o esperma e, por isso, está mais expostas ao risco de exposição ao HIV. Isso, sem dúvida, precisa ser ressaltado, mas não com a ênfase atual, que permite supor uma omissão por parte dos produtores de materiais. Afinal, os grandes responsáveis por "convencer" o homem a usar o preservativo são os educadores em saúde. E o homem, na maioria dos materiais, não é suficiente ou eficazmente estimulado a usar o preservativo: incentiva-se o uso e mostram-se os benefícios "abstratos" daí advindos (preservação da saúde, prevenção das DST, redução ao mínimo dos riscos de exposição ao HIV, proteção da parceira), mas não se mostram os benefícios "concretos" (possibilidade de manter relações casuais seguras, de "pular a cerca" sem correr riscos e/ou de manter relações com parceiras diferentes, prevenção da gravidez não-desejada), perfeitamente coerentes com os "scripts" sexuais prevalentes para uma grande parcela dos homens sexualmente ativos.

- A maior carga de responsabilidade colocada sobre os ombros da mulher nem sempre é acompanhada por maiores informações e orientações sobre como negociar o uso do preservativo. A cartilha Saúde Reprodutiva e AIDS (dirigida a mulheres adultas), por exemplo, não contém orientações sobre a negociação - o que é feito de maneira bastante criativa e eficaz no Gibi da DST/AIDS, na cartilha Toda Vez e Sempre e no folder Derrube Esta Barreira, também dirigidos 
a mulheres adultas. Contudo, há alguns materiais que, virtualmente, derrubam qualquer estímulo à negociação do uso da camisinha. Com efeito, no video Contos Modernos (dramatização orientada à prevenção das DST/AIDS das histórias infantis centradas nas personagens Chapeuzinho Vermelho, Rapunzel, Bela Adormecida e Cinderela), as quatro personagens tentam fazer com que seus respectivos parceiros sexuais usem o preservativo, mas somente a Cinderela é bem-sucedida. Se o objetivo é estimular e orientar as mulheres a negociarem o uso do preservativo, não seria mais eficaz exemplificar com negociações bemsucedidas? De que modo as mulheres vão se sentir motivadas a tentar uma negociação, desde o início, fadadas ao fracasso - como aconteceu em três das quatro histórias? No vídeo Mancha de Batom, igualmente, a negociação do uso do preservativo é extremamente difícil e mal-sucedida. Por sua vez, os homens não precisam, propriamente, de orientações quanto à negociação, mas sim quanto a estratégias de justificação do uso, a fim de responder a uma questão importante, levantada nos grupos focais por uma participante, que disse: "Se a gente vai pra cama com um cara e ele põe a camisinha, a gente logo pensa que ele tá doente ou que transa com todo mundo".

- 0 preservativo é apresentado, na quase totalidade dos materiais, como um elemento a mais na relação sexual, um participante cuja presença destina-se a dar proteção aos dois parceiros sexuais. 0 apelo à proteção, porém, não temse mostrado muito eficaz, basicamente porque, em primeiro lugar, os riscos de se contrair alguma enfermidade em geral são intangíveis e, em segundo lugar, porque a AIDS, para a grande maioria das pessoas é um fenômeno "distante", "não presente na realidade cotidiana de cada um" e que se relaciona ao "outro", jamais ao “eu”, como demostram 
diversos estudos a respeito. Assim, é preciso modificar o enfoque do preservativo, mostrando-o como um elemento erótico a mais, capaz de - aliado à proteção que proporciona - contribuir para a maior intimidade entre os parceiros, maior excitação e muito, muito prazer. Esse enfoque foi aplicado de forma bastante criativa e eficaz, por exemplo, na história em quadrinhos Onde Mora o Perigo, em que Monalisa (uma trabalhadora sexual) faz sexo oral, vaginal e anal com Antônio (personagem que, até então, se recusava a usar camisinha), sempre com ele usando preservativo e obtendo um grande prazer. Outro exemplo de enfoque erótico do preservativo, adequado ao público-alvo, é o folder Amor a Três (dirigido a homens bissexuais) que, numa linguagem que vai crescendo em erotismo, mostra os intensos prazeres possiveis numa transa a três, em dois momentos distintos: ele, ele e a camisinha; ele, ela e a camisinha. 0 slogan é chamativo e elucidativo: Um é pouco, dois é bom, mas três é melhor ainda. 0 terceiro elemento da transa, evidentemente, é sempre o preservativo.

- Um enfoque extremamente infeliz e inoportuno é o adotado nos materiais dirigidos a turistas que chegam ao Brasil. 0 folder Brasil: Terra dos Prazeres, por exemplo, começa a pecar pelo título. Além disso, o uso dos símbolos dos sexos masculino e feminino no fundo da capa também reforça o apelo à sexualidade e ao prazer. Em outro folder, também dirigido a turistas que vêm para o carnaval, podese ler: "0 Brasil espera por você. Pronto para realizar todas as suas fantasias". Afinal, o que se pretende é informar e educar para a prevenção das DST/AIDS ou incentivar o turismo sexual? Fica-se na dúvida, porque a sensualidade dos brasileiros e brasileiras é decantada como "uma atração a mais para muitos turistas". 
Ainda sobre o enfoque e abordagem das questões relacionadas às DST/ AIDS, deve-se ressaltar uma questão da mais alta relevância: a banalização do problema, concretizada sobretudo nas campanhas mais recentes, com os personagens "Bráulio" e "Peru", mas também em peças mais antigas, como os spots para TV intitulados Apoteose do Prazer, Medo de Afinar, Mulherengo e Brincando. Embora esses materiais e peças tenham se destinado à veiculação pelos meios de comunicação de massa - o que implica na não-segmentação e, por conseqüência, na superficialidade e pasteurização das mensagens -, não deixa de surpreender o tratamento vago, pouco sensivel e quase cômico dado ao tema. Com efeito, como se destacou nos grupos focais, "ora o Ministério diz que a AIDS é uma questão séria e que todos devem se cuidar, ora a trata em tom de brincadeira. Afinal, se a gente deve levar a AIDS a sério, cabe ao Ministério também abordá-la de forma séria".

0 que se observa, neste caso, é uma certa confusão entre os conceitos de popularização e banalização. Sem dúvida, as campanhas informativas disseminadas pelos meios de comunicação de massa e, especialmente, pela TV constituem uma contribuição altamente significativa para que a população em geral se informe sobre a doença. Na verdade, foi por meio da televisão que a maioria das pessoas tomou conhecimento, pela primeira vez, da existência da AIDS e da infecção pelo HIV de importantes personalidades nacionais e internacionais, o que chamou a atenção para a doença, fazendo com que ela entrasse na ordem do dia e se popularizassem os conhecimentos sobre a mesma e sua gravidade. Nos grupos focais, tanto de produtores quanto de segmentos selecionados, concluiu-se que a população em geral já possui bastante informação sobre a AIDS - graças, em parte, às campanhas massivas.

Contudo, também se concluiu que ter conhecimento e dispor de informações não são suficientes para criar as condições que dão origem a mudanças efetivas de práticas, atitudes e comportamentos, requeridas para a prevenção das DST/AIDS. Neste sentido, as campanhas massivas mais recentes estariam "chovendo no molhado", ou seja, veiculando informações para um público em geral já suficientemente informado, além de sugerir que o conhecimento torna a doença mais próxima, 
intima e, assim, pode-se até brincar com ela. $\mathrm{E}$ isso não é verdade. A AIDS continua a ser percebida como uma ameaça distante pela maioria das pessoas e não é tratando-a como coisa banal que se vai mudar a atitude da população.

\section{Aspectos de Linguagem e Vocabulário}

Em geral, não se observam grandes problemas quanto à linguagem e vocabulário predominantes nos materiais. Na maioria deles, ao contrário, tanto a linguagem quanto o vocabulário são adequados aos respectivos públicos-alvo. Dignos de destaque, a este respeito, são os folders Você Precisa Aprender a Transar com a Existência da AIDS e Rapaz da Noite. 0 primeiro, dirigido a adolescentes, começa falando dos "sonhos e ideais" que todo adolescente tem e quer ver realizados. Passa as informações de forma clara e objetiva, utilizando termos e expressões de uso comum pelo público-alvo, como se pode constatar no seguinte trecho: "A AIDS tem pintado por aí, todo mundo grilado. Ai, galera, resolvi me informar pra valer (...) Além disso, a AIDS está ligadona com o lance do meu (nosso) tesão”.

0 segundo folder, destinado a trabalhadores sexuais do sexo masculino (michês), também adota uma linguagem explícita e objetiva, recorrendo inclusive ao uso de expressões consideradas "chulas ou de baixo calão", mas comumente utilizadas nos ambientes e situações mais informais. Assim, quando expõe as práticas sexuais de maior risco quanto à exposição ao HIV, o educador opta por alinhar, ao lado das expressões formais, as expressões correspondentes na linguagem chula que, todavia, é bem aceita pelo público-alvo:

Contágio comprovado:

Sexo anal (comer ou dar o $\mathrm{cu}$ )

Sexo vaginal (comer ou dar a boceta)

Contágio provável:

Sexo oral ativo (chupar o pau, a boceta ou o cu)

Sexo oral passivo (ser chupado no pau ou no $\mathrm{cu}$ ) 
Entre os problemas observados, o mais importante é o uso de linguagem pouco clara e que pode induzir o público-alvo a interpretações equivocadas - o que, todavia, não é freqüente. No Gibi da DST/AIDS, por exemplo, a personagem Mariléia afirma que "a AIDS também é uma doença sexualmente transmissivel. É transmitida por sangue, esperma e outras secreções corporais." No caso, além do fato de que a pessoa só poderá se infectar se o sangue e o esperma estiverem contaminados pelo HIV, a expressão “outras secreções corporais” pode dar margem à interpretação de que também o contato com a urina, o suor, a saliva e/ou as lágrimas de pessoa portadora do HIV ou doente de AIDS poderia transmitir o virus, o que ainda não foi comprovado. Outros problemas, estes de menor importância, são:

a) Em alguns materiais ainda se utiliza a expressão “doenças venéreas" (Folder Pra Quem É Entendido no Assunto), há muito em desuso;

b) Nos folders dirigidos a homens que fazem sexo com homens, este público aparece identificado como "homossexuais" (Pra Quem É Entendido no Assunto), termo por eles considerado preconceituoso e estigmatizante. 0 mesmo ocorre com a denominação "prostituta" que, no entanto, aparece em materiais destinados a mulheres profissionais do sexo (Trabalhe com Segurança);

c) A AIDS, em uns poucos materiais é referida como "essa maldita doença". Isso contribui não apenas para estigmatizar os doentes como também para alimentar crenças infundadas a respeito, como as que associam AIDS a castigo divino, coisa do diabo, etc.;

d) Em alguns vídeos, as personagens (Chapeuzinho Vermelho e Rapunzel) sequer identificam o preservativo pelo nome, chamando-o de "isso" ou "isso daqui".

\section{Conclusões e Recomendações}

Ao longo desta análise, apontaram-se diversas virtudes e problemas que puderam ser observados nos materiais e campanhas de prevenção às 
DST/AIDS produzidos diretamente e/ou sob a responsabilidade de órgãos governamentais (CN DST/AIDS e Secretarias Estaduais de Saúde) e nãogovernamentais (ONGs diversas que atuam na área). Mais problemas que virtudes, é verdade. Contudo, isso não diminui a importância do trabalho realizado por esses órgãos, sobretudo pela CN DST/AIDS, que é o grande impulsionador e condutor das ações de prevenção às DST/AIDS no Brasil, cuja linha de ação mostrou-se tão eficaz na difusão de informações à população em geral e, também, a segmentos sociais selecionados que foi adotada como modelo pela própria OMS.

Presentemente, porém, a CN DST/AIDS precisa resgatar seu caráter pioneiro e vanguardista, dando um passo adiante, no sentido não mais de informar e motivar, e sim, de criar condições para que os diferentes segmentos sociais adquiram maior autonomia para preservar e melhorar seus niveis de saúde sexual. Sem dúvida, há necessidade de que se desenvolvam ações de natureza verdadeiramente educativas (e não, simplesmente, informativas ou motivacionais), tendentes a instaurar as mudanças de atitudes, comportamentos e práticas que a prevenção das DST/AIDS. Dirigidas tanto à população em geral quanto a segmentos com maiores probabilidades de exposição ao HIV, essas ações requerem uma completa mudança no modelo de comunicação hoje utilizado. As recomendações a seguir fundamenta-se nesse princípio geral e buscam contribuir para que as ações da CN DST/AIDS possam ser mais efetivas, em seu objetivo de criar condições para a adoção de comportamentos mais seguros.

\subsection{Quanto à Forma, Meios e Materiais}

1. Definir mix de materiais adequados aos públicos-alvo selecionados, inclusive com o uso sistemático de meios alternativos e comunitários de comunicação.

2. Elaborar vídeos educativos de média duração (12 a 15 minutos), para serem utilizados pelos multiplicadores nos projetos ou programas de aproximação. 
3. Enfatizar o uso do rádio, que tem sido o grande "esquecido" nas ações de comunicação para a prevenção das DST/AIDS. Devese criar mensagens e peças específicas para rádio, e não, utilizar o áudio dos spots de TV. No plano de mídia, as rádios locais e comunitárias e os serviços de alto-falantes devem ter prioridade, pois são mais eficazes para influenciar os públicos que os meios de comunicação de massa.

4. Demonstrar à área de comunicação social do Governo que a prevenção das DST/AIDS envolve especificidades que exigem segmentação da audiência, mensagens adequadas aos diferentes públicos-alvo e seleção precisa da mídia a ser utilizada, bem como o tempo de permanência e duração das campanhas. Isso implica em que deve caber à própria CN DST/AIDS as decisões quanto aos meios e veículos a serem utilizados, o número de inserções e horários de inserção das peças/mensagens.

\subsection{Quanto às Mensagens, Conteúdos e Linguagem}

5. Em todos os materiais e peças de campanhas, privilegiar conteúdos educativos e formativos, em detrimento da simples informação. É preciso abordar com maior freqüência e profundidade os diferentes aspectos comportamentais que facilitam ou dificultam a exposição ao HIV e menos as informações sobre características, sintomas e efeitos da doença, de resto já bem conhecidos pela população.

6. Os benefícios tangiveis e intangiveis da adoção de novos comportamentos e práticas precisam estar claros, para que provoquem a reflexão e tomada de decisão consciente, e não, difusos e implícitos, como muitas vezes aparecem nos materiais.

7. Difundir o uso do preservativo como estratégia de sexo seguro é fundamental. Porém, aliadas a esta, outras medidas devem ser contempladas, como o sexo não-penetrativo, redução do número de parceiros ou monogamia, fidelidade mútua. 
8. Trabalhar melhor as diferentes mensagens, em termos de conteúdos, forma, linguagem e enfoque, a fim de torná-las mais aceitáveis aos diversos públicos-alvo, bem como evitar possiveis interpretações equivocadas ou a manutenção de mitos e preconceitos relacionados às DST/AIDS e às estratégias de prevenção.

9. Verificar, com profundidade, a uniformidade de conteúdo num mesmo material e entre diferentes materiais, para que não haja contradições nas mensagens, o que afeta a credibilidade tanto do material em si quanto da fonte das informações.

10. Enfatizar ações simples, mas ainda não suficientemente esclarecidas junto aos diferentes segmentos da população. Por exemplo: ensinar como desembalar corretamente o preservativo, verificar a data de validade e as condições do produto; como cortá-lo adequadamente para a prática do sexo oral; como esterilizar seringas e agulhas. Também se deve enfatizar o tempo que pode decorrer entre a infecção pelo HIV e o aparecimento dos primeiros sintomas de AIDS, o mesmo ocorrendo com a possibilidade de infecção em corrente e as interrelações entre uso de drogas e menor inclinação para a prática do sexo seguro.

11. Enfatizar as estratégias de negociação do uso do preservativo, tanto nos materiais dirigidos a mulheres adultas, jovens e adolescentes quanto a homens que fazem sexo com homens, trabalhadores sexuais e mulheres/parceiras de homens bissexuais, usuários de drogas injetáveis ou internos do sistema penitenciário.

12. Enfatizar as estratégias de erotização do preservativo, que é a chave para incentivar um uso mais amplo e consistente do produto.

13. Evitar a tendência de banalização da questão da AIDS, tratandose sempre de forma séria, clara e consistente, sem subterfúgios mas também sem provocar temores desnecessários e crenças infundadas, como deseja a maioria dos públicos-alvo; 


\subsection{Quanto ao Enfoque e Abordagem}

14. Adotar o principio de que a questão não é meramente emergencial, e sim, de natureza estrutural. Assim, perde validade o enfoque publicitário até aqui adotado. Esse enfoque foi válido para difundir, rápida e amplamente, informações básicas sobre a doença. Contudo, ele não é eficaz no processo de adoção de mudanças comportamentais.

15. Assumir que é responsabilidade dos educadores em saúde educar o homem para a prática do sexo seguro, principalmente com o uso do preservativo. Enfatizar esse ponto nas mensagens dirigidas a adolescentes e jovens e homens adultos.

16. Em todos os materiais e peças, adotar sempre um enfoque positivo, dando prioridade às mensagens que mostram os benefícios de se adotar comportamentos e práticas seguras, em vez de mostrar os malefícios oriundos de práticas de risco.

17. Utilizar mais amplamente os modelos de demonstração e testemunho, inclusive com prioridade para o uso de porta-vozes efícazes juntos aos diversos públicos.

18. Enfocar e abordăr, sempre, as questões relacionadas às DST/ AIDS sab a perspectiva da saúde, de sua preservação e melhoria, e não, sob perspectiva da doença.

\subsection{Quantos aos Modelos e Estratégias}

19. Há necessidade de maior segmentação do público-alvo a que se destinam os diferentes materiais e campanhas. Isso é importante porque permite que se fuja da informação genérica e superficial que caracteriza os materiais e peças dirigidos à população em geral, utilizando-se mensagens especificas para públicos especificos. 
20. Deve-se realizar, estimular e apoiar estudos e pesquisas junto a segmentos sociais especificos a fim de levantar eventuais mudanças e variações comportamentais, de modo a fundamentar, cientificamente, as futuras ações informativo-educativas.

21. Alguns públicos-alvo precisam ser, enfim, contemplados pelas ações de informação e educação. Estão neste caso, por exemplo, os analfabetos, mulheres casadas ou unidas com homens que fazem sexo com homens e/ou com usuários de drogas injetáveis, caminhoneiros, internos do sistema penitenciário e meninos e meninas internos em instituições correcionais, para os quais não se identificou qualquer material especifico.

22. Há necessidade de estimular maior compartilhamento de materiais entre as diferentes 0 Gs e $0 \mathrm{NGs}$ que atuam na área. $0 \mathrm{~s}$ materiais são, em geral, redundantes em termos de mensagens, conteúdos e enfoques, o que equivale a dizer que dois ou três deles seriam eficazes para cumprir os objetivos hoje alcançados com 10 ou mais diferentes materiais. A economia de recursos dai advinda permitiria produzir novos materiais, a fim de atender aos novos públicos-alvo definidos a partir da maior segmentação.

23. Identificar profissionais-chave nos OGs e ONGs, responsáveis pela produção e uso de materiais de IEC, e capacitá-los nos aspectos que envolvem a comunicação para a prevenção das DST/AIDS: segmentação e definição dos públicos-alvo; as metas e objetivos (quantitativos e qualitativos); as mensagens básicas; seleção de materiais e meios; definição do enfoque e abordagem; metodologias de uso e avaliação.

24. As especificidades comportamentais da população requerem diferentes mensagens, estratégias e metodologias de aproximação e intervenção. Neste sentido, as ações de comunicação possuem eficácia limitada, uma vez que estão centradas no componente promoção (tanto do problema quanto de sua solução). É preciso implantar uma estratégia de marketing social, com a definição precisa dos diferentes produtos sociais que a CN DST/AIDS tem a oferecer, os preços tangiveis e intangiveis desses produtos, sua promoção e pontos de distribuição, o pessoal envolvido em todos os niveis. 
25. Enfatizar a educação nas escolas, com a implementação da Portaria Conjunta dos Ministérios da Saúde e da Educação, que determina a implementação de ações educativas para a prevenção das DST/AIDS, em todos os niveis de ensino.

26. Utilizar métodos e estratégias pelos quais as pessoas possam reconhecer as DST/AIDS como um problema possivel em sua realidade cotidiana, reduzindo a crença de que sobretudo a AIDS é um problema distante, do "outro".

\subsection{Quanto à Metodologia de Uso/Difusão e Avaliação}

27. Implantar, para todos os materiais de produção direta, conveniada ou contratada, o mapa de controle da produção e difusão/uso de materiais de IEC, que deverá estar preenchida desde o inicio do processo de produção, a fim de orientar esse processo e o uso e formas de difusão do material, além de suas avaliações.

28. Incluir nas normas para apresentação de projetos de produção de materiais e campanhas, o Guia de Produção e Uso de Materiais de IEC devidamente preenchido. Deste modo, a CN DST/AIDS terá melhores condições para avaliar a necessidade, relevância e adequação do material ou campanha às suas diretrizes gerais e específicas, bem como de promover o compartilhamento de materiais entre $0 \mathrm{NGs}$.

29. Definir e implementar estratégias de avaliação de processo (grupos focais) e de resultados das campanhas e materiais, compartilhando as lições aprendidas (feedback). 